\title{
Fabrication of Ocular Prosthesis for Phthisis Bulbi by an Innovative Impression-Less Technique - A Case Report
}

\author{
Sanath Shetty ${ }^{1}$, Hasan Sarfaraz ${ }^{2}$, Naresh Shetty ${ }^{3}$, Syed Ghouse Ahmed ${ }^{4}$ \\ 1, 2, 3, 4 Department of Prosthodontics, Yenepoya Dental College, Deralakatte, Mangalore, India.
}

\section{INTRODUCTION}

Phthisis bulbi is an ocular condition caused by wound healing secondary to severe trauma, inflammation, or necrotising tumours of the eye. It represents an ocular endstage disease characterised by atrophy, shrinkage, disorganisation of the eyeball, and intraocular contents. Disfigurement associated with the eye can cause significant physical and emotional disturbance. Prosthetic rehabilitation over the residual eyeball is the preferred treatment of choice over surgical intervention such as enucleation or evisceration. Treatment of such patients is challenging and a multidisciplinary approach is required to provide a satisfactory ocular prosthesis. This case report describes the prosthetic management of a patient with phthisis bulbi by a novel impression-less technique.

The initial unsaid communication that takes place between two individuals is through their "eyes". A confident person will always maintain eye contact while conversing. They are the organs of the visual system which are sensitive to various stimuli. ${ }^{1}$ Any anomaly involving the eyes causes psychological, emotional, and aesthetic trauma to the patient. Phthisis bulbi is an ocular condition due to multifactorial conditions such as delayed wound healing secondary to severe trauma, infections such as keratitis, uveitis and endophthalmitis. Also, some failed surgical procedures including cataract, glaucoma, retinal surgery and intraocular malignancies like choroidal melanoma, retinoblastoma as well as systemic diseases like diabetes or hypertension may result in phthisis bulbi.2,3

The name "Phthisis bulbi" comes from a Greek word which means "to waste away" or "shrinkage. It is a histopathological diagnosis of end-stage non-functional ocular disease showing atrophy, shrinkage, and disorganisation of the eye and intraocular contents. Clinically, the eyes have no perception of light due to intraocular calcium deposition within band keratopathy, cataractous lens, sclera, gliotic neural retina, or within an optic nerve in the phthisical eye. ${ }^{4}$

Surgical procedures are not desired in a patient of phthisis bulbi unless it becomes painful. Hence, prosthetic rehabilitation is the only preferred treatment of choice in the patient with phthisis bulbi. ${ }^{5}$

A properly fabricated custom-made prosthesis enhances the patient's comfort, confidence, and aesthetics by increased adaptiveness, natural appearance, and functional stimulation. ${ }^{6}$ Hence, we devised an innovative approach to fabricate an ocular prosthesis for a patient suffering from phthisis bulbi by using an impression less technique which has been described in this case report.
Corresponding Author:

Dr. Naresh Shetty,

Reader, Department of Prosthodontics,

Yenepoya Dental College, University road,

Deralakatte, Mangalore, India.

E-mail: nareshhgshetty85@gmail.com

DOI: $10.14260 /$ jemds/2021/99

How to Cite This Article:

Shetty S, Sarfaraz $H$, Shetty $N$, et al. Fabrication of ocular prosthesis for phthisis bulbi by an innovative impression-less technique - a case report. J Evolution Med Dent Sci 2021;10(07):450-453, DOI: $10.14260 /$ jemds/2021/99

Submission 05-10-2020,

Peer Review 10-12-2020,

Acceptance 17-12-2020,

Published 15-02-2021.

Copyright (c) 2021 Sanath Shetty et al. This is an open access article distributed under Creative Commons Attribution License [Attribution 4.0 International (CC BY 4.0)] 


\section{PRESENTATION OF CASE}

A 57-year-old male patient was referred to the Department of Prosthodontics, Yenepoya Dental College and Hospital, with a chief complaint of blindness in the right eye [Figure 1]. History revealed that his right eye was operated on for cataract 16 years back, following which there was an infection. Due to negligence and financial constraints, medical care could not be administered on time which led to the loss of vision.

The patient was referred to an ophthalmologist at Yenepoya Medical College and Hospital for thorough clinical evaluation and was diagnosed with phthisis bulbi. Also, his left eye was operated on for pars plana vitrectomy. Such longstanding cases lead to loss of vision. Hence, his left eye was saved by this procedure.

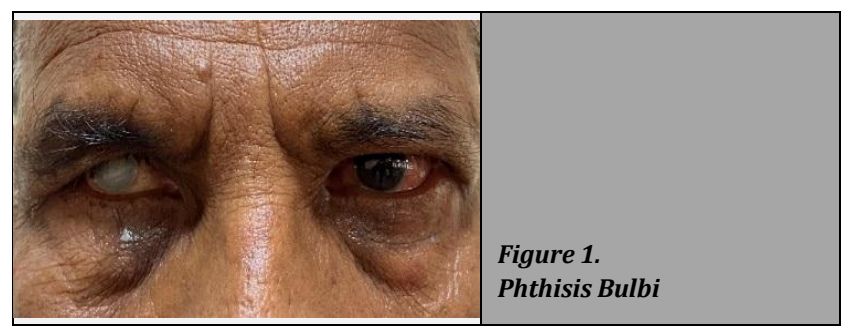

\section{DISCUSSION OF MANAGEMENT}

According to treatment-based classification given by Aggarwal et al.,7 this condition is I-b corneal opacity with no enophthalmos and normal sclera with corneal sensitivity. It was decided to fabricate an ocular prosthesis to be fitted over the phthisis bulbi to improve the aesthetic appearance and psychological well-being of the patient. The treatment plan was thoroughly explained to the patient and informed consent was obtained.

As the eyes were sensitive to the conventional impression technique, we developed an ingenious technique. The procedure started with the selection of a stock shell that fits his eyes comfortably, with the patient able to perform all eye movements. After the selection of the appropriate size of the stock shell, it was duplicated using addition silicone elastomeric impression material (Zhermack-Hydrorise, putty normal set, Italy) [Figure 2a and 2b]. The base and catalyst of the putty consistency addition silicone were mixed according to the manufacturer's instructions. An impression of the intaglio surface was made over this putty consistency silicone, taking care that the putty does not flow onto the cameo surface of the stock shell. An index of the intaglio surface of the stock shell was obtained after which petrolatum jelly was applied as a separating medium on the border of the index. After this, base and catalyst paste of addition silicone was mixed according to the manufacturer's instructions and an impression of the cameo surface was made over this index with the stock shell embedded in it. The two indices are separated carefully after a complete set and an assembly as shown in [Figure 2b] was obtained. An access hole was made using a Lecron carver at the center of the index on the side of the cameo surface as shown in [Figure 2a].

Modelling wax (Hindustan modelling wax no 2, Hyderabad, India) was melted and poured into the access hole as shown in [Figure 2a], followed by which scleral wax pattern was allowed to cool [Figure 2c]

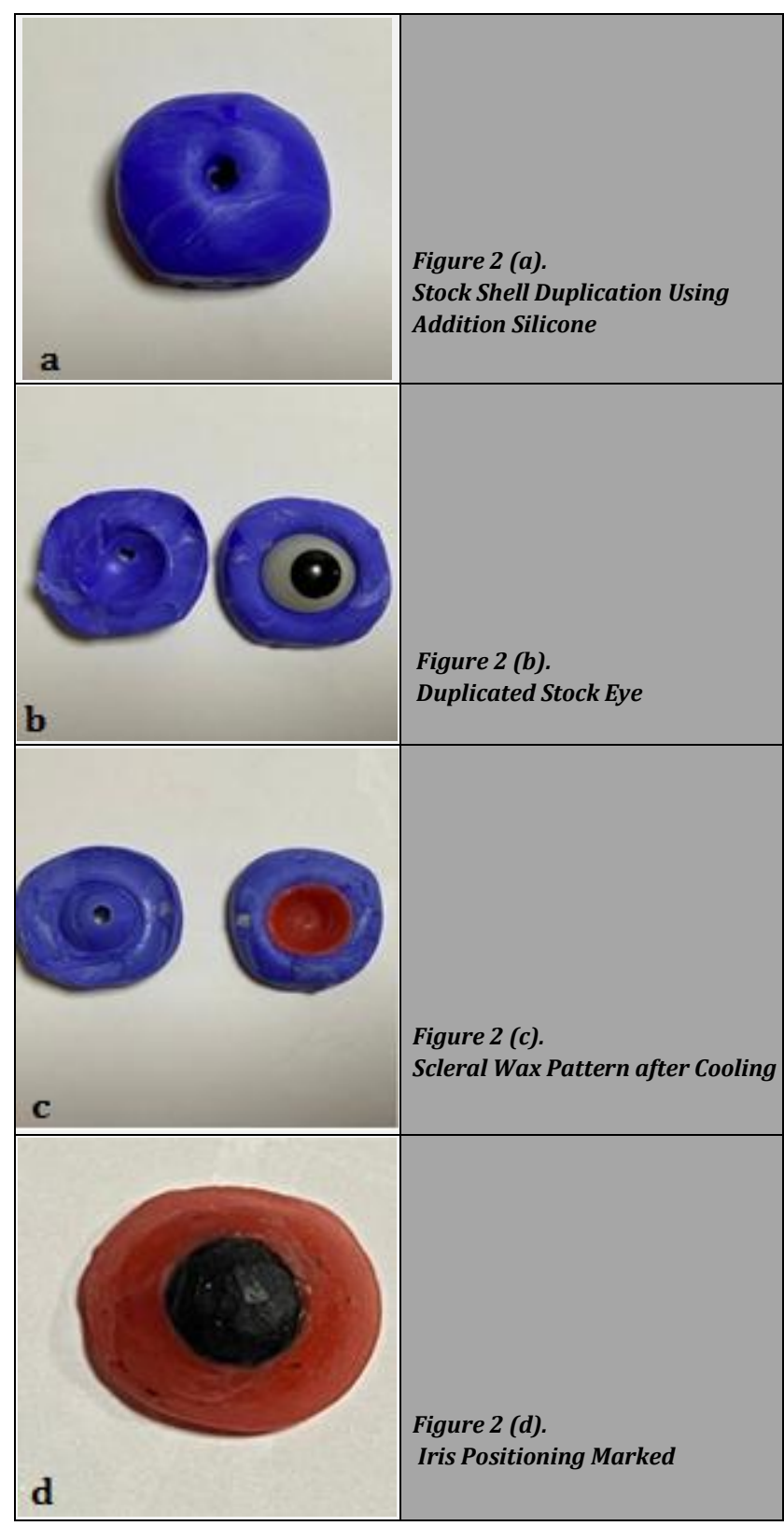

Iris was fabricated using clear cold cure acrylic resin (DPI cold cure, Mumbai, India). Black acrylic paint (Pidilite Fevicryl, Mumbai, India) was added while mixing clear cold cure acrylic resin. Wax pattern try-in was done to assess the contour. The upper and lower margin of the contralateral iris was marked using a divider with a blunt end.

Iris was positioned on the wax pattern [Figure 2d] for evaluation of contour and gaze [Figure 3a] by asking the patient to look at the distant object with a neutral gaze, multiple photographs were taken and iris position was determined.

Shade tabs of tooth molding material (DPI Mumbai, India) were used for colour matching and the approximate shade was selected [Figure 3b].

Wax pattern was invested in an ocular flask and acrylization was done using a compression molding technique with a short curing cycle $\left(65^{\circ} \mathrm{C}\right.$ for 90 minutes) using heat cure tooth molding material of the selected shade [Figure 3c]. 

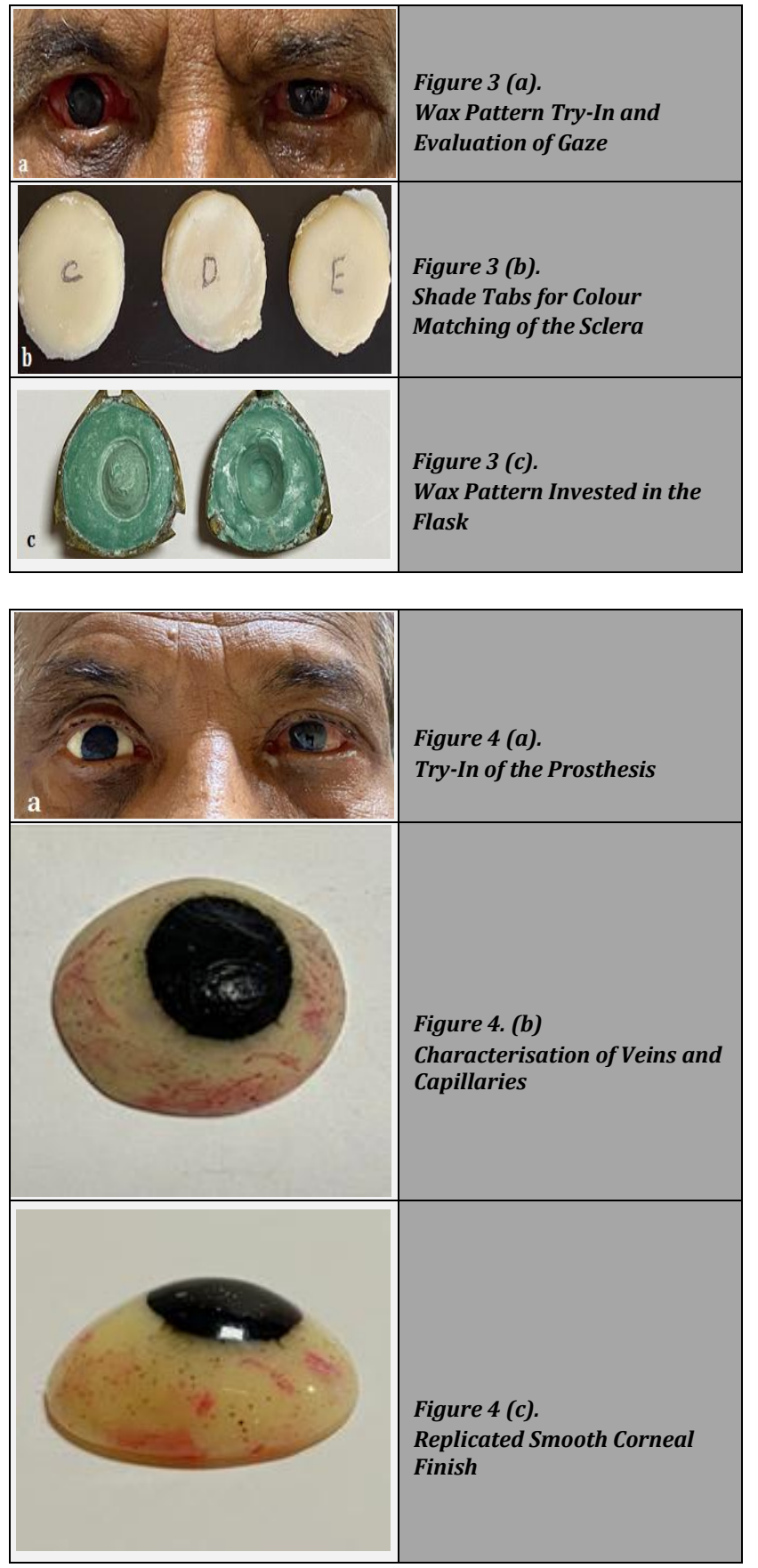

After acrylization, the eye prosthesis was removed and excess material was trimmed. It was rechecked in the patient's eye to assess the contour and iris position after which $1 \mathrm{~mm}$ contour thickness was scraped [Figure 4a].

Characterisation of veins and capillaries was done using acrylic paint (Pidilite Fevicryl, Mumbai, India) on the prosthesis, after try-in [Figure 4b]. The characterised eye prosthesis was again acrylized in the same flask. $1 \mathrm{~mm}$ contour thickness, which was scrapped, was used to accommodate the clear heat cure acrylic resin (DPI Mumbai, India) to get a smooth corneal finish [Figure 4c].

The excess material in prosthesis was trimmed using acrylic trimming burs (Kavyanjali, Rajasthan, India) and finishing was done using emery paper on a sandpaper mandrill (Cutfast, silicon carbide waterproof paper, P320). After obtaining a smooth surface, the prosthesis was polished using pumice powder (Prevest Denpro, India) and cotton buff (Renfert, Germany).

The eye prosthesis was inserted after disinfection and checked for all the movements [Figure 5]. Once the patient was comfortable with the prosthesis, he was shown the method of insertion and removal of the prosthesis with a face mirror in his hand and was made to practice the same. The patient was instructed to remove the prosthesis at night and clean with antibacterial soap water and instructed to store it in a small container filled with saline solution.

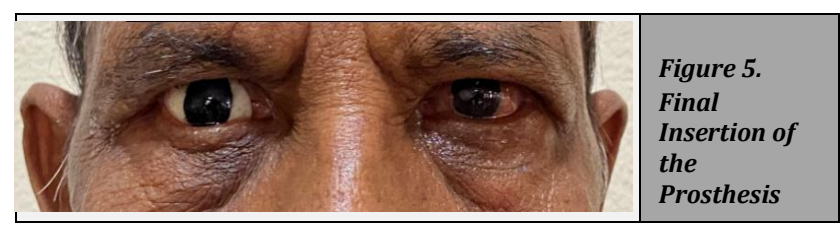

\section{CLINICAL DIAGNOSIS}

Phthisis bulbi of the right eye.

\section{DIFFERENTIAL DIAGNOSIS}

Retinoblastoma, bony tumours (osteoma), osteogenic sarcoma, and uveal melanoma.

\section{PATHOLOGICAL DISCUSSION}

As time progresses, atrophy of the globe leads to hypotony and shrinkage while maintaining the structure of the eye (atrophia bulbi). A phthisical globe shows a small squared-off shape, opaque and thickened cornea, thickened sclera, neovascularisation of iris, cataract, cyclitic membrane, ciliochoroidal detachment, and retinal detachment.

Microscopic features include internal disorganisation, inflammatory reaction, reactive proliferation of various cells, calcification, and ossification.

Even on computed tomography (CT) scan, intraocular structures cannot be identified easily and there is often calcification seen within the eye. ${ }^{8}$ In phthisis bulbi, intraocular calcium may be deposited within a cataractous lens, sclera, a gliotic neural retina, or optic nerve. ${ }^{4}$

Hence, cosmetic rehabilitation of these facial disfigurements fabricated using custom-made prosthetic devices enhances social acceptance and improves their quality of life. However, difficulties with facial prostheses arise due to movable tissue beds, quality of prosthesis retention, and associated irritation of the tissue beds. ${ }^{9}$ Hence, a multidisciplinary approach is essential in providing precise and effective rehabilitation and follow-up care for these patients.

A custom-made prosthesis provides a very close approximation of the scleral shell which allows even distribution of volume and weight in the socket providing better mobility, improved appearance, less discomfort to the patient in comparison to a stock prosthesis which has very 
poor apposition to the tissue beds and leads to irritation of the tissue and accumulation of the tear fluid. ${ }^{10}$

For a patient who needs an ocular prosthesis, the fabrication begins with a conventional approach by making an impression with silicones or irreversible hydrocolloids by various techniques such as direct impression, impression with a stock tray, modified stock tray or custom ocular tray, impression with a stock ocular prosthesis, etc. After this procedure, the wax pattern is fabricated by pouring the cast using the impression made. Once the wax pattern is checked in the patient eye for proper contours, movement, and margins, the gaze of the patient is marked and iris is incorporated in the wax pattern by observing colour, diameter. Different techniques including conventional painting, mixing monomerpolymer on the artificial iris, using digital hard and soft copy images of the patient's healthy eye, using grids, marking even measurements from the middle of the face, etc., can be used in iris positioning. ${ }^{11}$ Once the clinician and the patient are satisfied with the contours, movements, and margins the wax pattern is acrylized using heat cure acrylic resin. This partially finished prosthesis is tried in the patient's eye before a layer of clear heat-cure acrylic resin is applied to this to get a final finish, after which the prosthesis can be delivered to the patient. This approach is time-consuming and cumbersome.

In this case, the patient presented without any shrinkage of the eyeball and had a highly sensitive sclera. Hence, the conventional impression procedure for making custom eye prosthesis was not possible. Also, there isn't enough evidence in the literature that shows a proper method of fabrication of ocular prosthesis for phthisis bulbi. Hence, this case was treated with an innovative impression-less technique. In this technique, it not only enhanced comfort for the patient but it was also easy to fabricate a prosthesis within a day. The selection of proper stock eye enabled us to provide enough space between the sclera and the prosthesis so that the patient sclera was not sensitised or disturbed. Once the patient was comfortable with all the ocular movements putty impression was made to duplicate the stock eye. After obtaining the index, the modelling wax was melted and poured into the access hole to obtain the scleral wax pattern. The iris position was clinically marked using multiple photographs and an unfinished prosthesis was obtained.

Characterisation of capillaries and veins was done using acrylic paint and at the end, acrlylization (short curing cycle) was done using clear heat cure acrylic resin to get a glossy corneal finish. Hence, aesthetics, function, and comfort were not compromised. Therefore, the advantage of this technique was simple, easy to fabricate, with improved facial contours, less time consuming as the prosthesis can be delivered within a day with improved and enhanced aesthetics. As the impression was not made the intaglio surface may not have perfect adaptation to the soft tissues and change of prosthesis may be needed. This can be the limitation of this technique.

The success of the ocular prosthesis largely depends on the precise laboratory technique and artistic skills of the operator. Rehabilitation of the phthisis bulbi with a prosthetic eye plays a major role in the psychological and social well-being of the patient. This case report demonstrates an easy and quick way to rehabilitate patients without making an impression which is considered the most painful step in the case of phthisis bulbi.

\section{FINAL DIAGNOSIS}

Phthisis bulbi of the right eye.

Financial or other competing interests: None.

Disclosure forms provided by the authors are available with the full text of this article at jemds.com.

\section{REFERENCES}

[1] Tripathy K, Chawla R, Temkar S, et al. Phthisis Bulbi - a clinicopathological perspective. Seminars in Ophthalmology 2018;33(6):788-803.

[2] Henke V, Philip W, Naumann GOH. Intraokulare Verknöcherungen bei klinisch unerwarteten malignen Melanomen der Uvea und bei Phthisis bulbi. Klinische Monatsblätter für Augenheilkunde 1986;189(09):243-6.

[3] Hadjistilianou T, De Francesco S, Marconcini S, et al. Phthisis bulbi and buphthalmos as presenting signs of retinoblastoma: a report of two cases and literature review. European Journal of Ophthalmology 2006;16(3):465-9.

[4] Chan CC, Fujikawa LS, Rodrigues MM, et al. Immunohistochemistry and electron microscopy of cyclitic membrane: report of a case. Archives of Ophthalmology 1986;104(7):1040-5.

[5] Naveen HC, Porwal A, Nelogi S. Prosthetic rehabilitation of phthisis bulbi by digital imaging technique-a case report. Contact Lens and Anterior Eye 2010;33(5):231-4.

[6] Beumer J, Zlotolow I. Restoration of facial defects. In: Beumer J, edr. Maxillofacial rehabilitation - prosthodontic and surgical considerations. St. Louis, Mo, USA: Mosby 1996: p. 350-64.

[7] Aggarwal H, Singh RD, Kumar P, et al. Prosthetic guidelines for ocular rehabilitation in patients with phthisis bulbi: a treatment - based classification system. The Journal of Prosthetic Dentistry 2014;111(6):525-8.

[8] Albert DM, Jakobiec FA. Principles and practice of ophthalmology. $1^{\text {st }}$ edn. W.B. Saunders Company, 1994: $\mathrm{p}$. 3513.

[9] Chang TL, Garrett N, Roumanas E, et al. Treatment satisfaction with facial prostheses. The Journal of Prosthetic Dentistry 2005;94(3):275-80.

[10] Raizada K, Rani D. Ocular prosthesis. Contact Lens and Anterior Eye 2007;30(3):152-62.

[11] Goiato MC, Bannwart LC, Haddad MF, et al. Fabrication techniques for ocular prostheses - an overview. Orbit 2014;33(3):229-33. 